\title{
Association between serum soluble tumor necrosis factor-a receptors and early childhood obesity
}

\author{
Shengrong Ouyang ${ }^{1)}$, Wei $\mathrm{Li}^{2)}$, Zhuo Liu ${ }^{1)}$, Yuanyuan $\mathrm{Li}^{1)}$, Sen $\mathrm{Li}^{1)}$ and Jianxin $\mathrm{Wu}^{1)}$ \\ 1) Dept. of Biochemistry, Capital Institute of Pediatrics, Beijing 100020, China \\ 2) Graduate School of Peking Union Medical College, Beijing 100730, China
}

\begin{abstract}
This study aimed to characterize the inflammatory cytokine profiles and further validate the significantly different cytokines in the serum obtained from obese children aged 36-48 months. Four obese children and four lean controls were randomly selected for inflammatory cytokine array assay, in which two cytokines [soluble tumor necrosis factor- $\alpha$ receptors (sTNFRs) 1 and 2] were found to be significantly different. Both cytokines (sTNFR1 and sTNFR2) were then further validated through enzyme-linked immunosorbent assay (ELISA) in 61 obese children and 52 lean children. ELISA results revealed that serum sTNFR1 level in obese children significantly increased $(p=0.003)$, whereas sTNFR2 did not change significantly $(p=0.069)$. Stratified analysis by gender showed that only obese girls presented increased sTNFR1 $(p=0.005)$ and sTNFR2 $(p=0.049)$ levels. We conclude that serum sTNFR1 is elevated in early childhood obesity. Moreover, serum sTNFR1 and sTNFR2 are associated with obese girls but not obese boys, thereby suggesting that serum sTNFRs in early childhood obesity may be sex related.
\end{abstract}

Keywords: Child obesity, Early childhood, sTNFR, Inflammatory cytokine

OBESITY and childhood obesity are major public health problems worldwide. Increasing evidence indicates that obesity is causally linked to a chronic lowgrade inflammatory state $[1,2]$. Obesity in childhood increases the risk of obesity in adulthood, which in turn, is associated with the development of obesityrelated disorders.

The chronic low-grade inflammatory state is characterized by elevated circulating levels of inflammatory cytokines and acute-phase proteins [3, 4]. A review [5] summarized that adipose tissue from lean individuals preferentially secretes anti-inflammatory adipokines, such as adiponectin and interleukin (IL)-10. In contrast, obese adipose tissue mainly releases proinflammatory cytokines, such as tumor necrosis factor (TNF)- $\alpha$, IL-6, and leptin. Some circulating cytokines, including TNF- $\alpha$, high-sensitive $\mathrm{C}$-reactive protein (CRP), IL-6 and adiponectin, have been correlated with human obesity [6-8]. Most of the knowledge on obesity-induced inflammation comes from studies in

Submitted Nov. 6, 2015; Accepted Mar. 14, 2016 as EJ15-0628

Released online in J-STAGE as advance publication Mar. 31, 2016

Correspondence to: Jianxin Wu, Dept. of Biochemistry, Capital Institute of Pediatrics, Road 2, Yabao, Beijing 100020, China.

E-mail: cipbiolab@163.com adults, adolescents, and older children. Only a few studies, such as those of Bocca et al. and Skinner et al., focused on very young children, and even then, they only examined a few markers of inflammation $[6,9]$. Early childhood obesity provides an excellent opportunity to study inflammatory changes without confounding lifestyle habits (e.g., smoking) and co-existing inflammatory conditions (e.g., cardiovascular disease or arthritis) [7]. Therefore, the data on relationship of obesity with very young obese children need to be enriched urgently.

In the present study, we characterize the inflammatory cytokine profiles in serum of obese children at 36-48 months, using a Quantibody ${ }^{\circledR}$ Human Inflammation Array. To the best of our knowledge, no study has comprehensively explored inflammatory cytokines profiles in preschool children, especially children distributed at a narrowed age range (e.g., 3-years-old). The inflammatory array has similar detection sensitivity as traditional enzyme-linked immunosorbent assay (ELISA), and allows the quantitative detection of 40 different inflammation-related cytokines simultaneously. Hence, this approach is used to identify novel inflammatory mediators associated with early childhood obesity. 


\section{Materials and Methods}

\section{Study population}

A total of 121 children aged 36-48 months, who participated in a physical check for kindergarten enrollment, were recruited in the study. Children with an underlying hormone deficiencies, genetic disorders, inflammatory conditions, or occurrences of recent acute infections were excluded. Among the participants, 4 obese children and 4 lean controls were randomly chosen for array analysis in the discovery set. In the validation set, the study cohort consisted of 113 other subjects, including 61 obese children [body mass index $(\mathrm{BMI})>18.5$ and $\left.<26 \mathrm{~kg} / \mathrm{m}^{2}\right]$ and 52 lean children (BMI $>13.5$ and $<15 \mathrm{~kg} / \mathrm{m}^{2}$ ). Obesity classification criteria refer to $\mathrm{BMI}_{28}$ of Chinese children aged 3 years [10]. The study was approved by the Institutional Ethics Committee of the Capital Institute of Pediatrics, Beijing, PR, China (SHERLLM 2012015).

\section{Sample collection}

Fasting blood samples were taken from the antecubital vein, and then centrifuged at room temperature for $10 \mathrm{~min}$ at $3,000 \times \mathrm{g}$. Aliquots of serum were stored at $-80{ }^{\circ} \mathrm{C}$ for subsequent use.

\section{Human inflammation array}

The collected serum was analyzed using the commercial arrays, Quantibody ${ }^{\circledR}$ Human Inflammation Array-3 (RayBiotech, Inc., USA), in accordance with the manufacturer's protocol. The multiplexed technology allowed simultaneous detection of 40 different cytokines.

\section{ELISA}

Levels of soluble TNF- $\alpha$ receptors (i.e., sTNFR1 and sTNFR2) were measured by ELISA according to the manufacturer's instructions (Catalog Nos. DRT100, sTNFR1; DRT200, sTNFR2; R\&D Systems, Inc., USA).

\section{Statistical analysis}

In the inflammation array assay, the results were expressed as means \pm standard deviation (SD). The difference for every cytokine between obese and lean children was compared using student's $t$-test. In ELISA, data were expressed as median (25th-75th percentile), and both groups (obese $v s$. lean) were compared by Mann-Whitney U tests for being non-normally distributed. The differences in age and BMI between obese and lean children were compared using student's $t$-test. Difference in terms of gender was analyzed using Chisquare test. Stratified analysis was performed according to gender difference between two groups (obese $v s$. lean). All analyses were performed using SPSS 13.0 (Chicago, IL, USA), and statistical significances were denoted by $p<0.05$.

\section{Results}

\section{Basic characteristics of studied children}

In the validation set, the basic characteristics of the recruited children are documented in Table 1. There exist statistically significant differences in gender $(p=0.008)$ and BMI $(p<0.001)$, but no statistically significant difference in age between the two groups (obese $v s$. lean). In the discovery set, the differences in terms of age, gender, and BMI between both groups were not compared for a small sample size (Supplementary Table 1).

\section{Inflammation array analysis}

The differences among the 40 cytokines were compared between obese and lean children. There were no significant differences in most of the measured parameters between the two study groups, except in serum sTNFR1 $(p<0.001)$ and sTNFR2 $(p=0.048)$. The results are shown in Supplementary Table 1 and Fig. 1.

Table 1 Characteristics of the participants in the validation set

\begin{tabular}{lccc}
\hline & Lean $(\mathrm{N}=52)$ & Obese $(\mathrm{N}=61)$ & $p$ \\
\hline Age (month), mean \pm SD & $39.9 \pm 3.1$ & $39.9 \pm 3.0$ & $0.978^{\text {a }}$ \\
Gender $($ male/female) & $16 / 36$ & $34 / 27$ & $0.008^{\mathrm{b}}$ \\
BMI $\left(\mathrm{kg} / \mathrm{m}^{2}\right)$, mean $\pm \mathrm{SD}$ & $14.1 \pm 0.6$ & $21.2 \pm 2.2$ & $<0.001^{\mathrm{a}}$ \\
sTNFR1, pg/mL $\left(\mathrm{P}_{25}-\mathrm{P}_{75}\right)$ & $815.7(703.7-916.3)$ & $911.5(773.0-1025.5)$ & $0.003^{\mathrm{c}}$ \\
sTNFR2, pg/mL $\left(\mathrm{P}_{25}-\mathrm{P}_{75}\right)$ & $2,166.9(1,891.2-2,534.8)$ & $2,257.2(2,087.2-2,731.6)$ & $0.069^{\mathrm{c}}$ \\
\hline
\end{tabular}

$\mathrm{P}_{25}, 25$ th percentile; $\mathrm{P}_{75}, 75$ th percentile; BMI, body mass index; sTNFR, soluble tumor necrosis factor $-\alpha$ receptor.

${ }^{\mathrm{a}}$ Student $t$ test, ${ }^{\mathrm{b}}$ Chi-square test, ${ }^{\mathrm{c}}$ Mann-Whitney test 

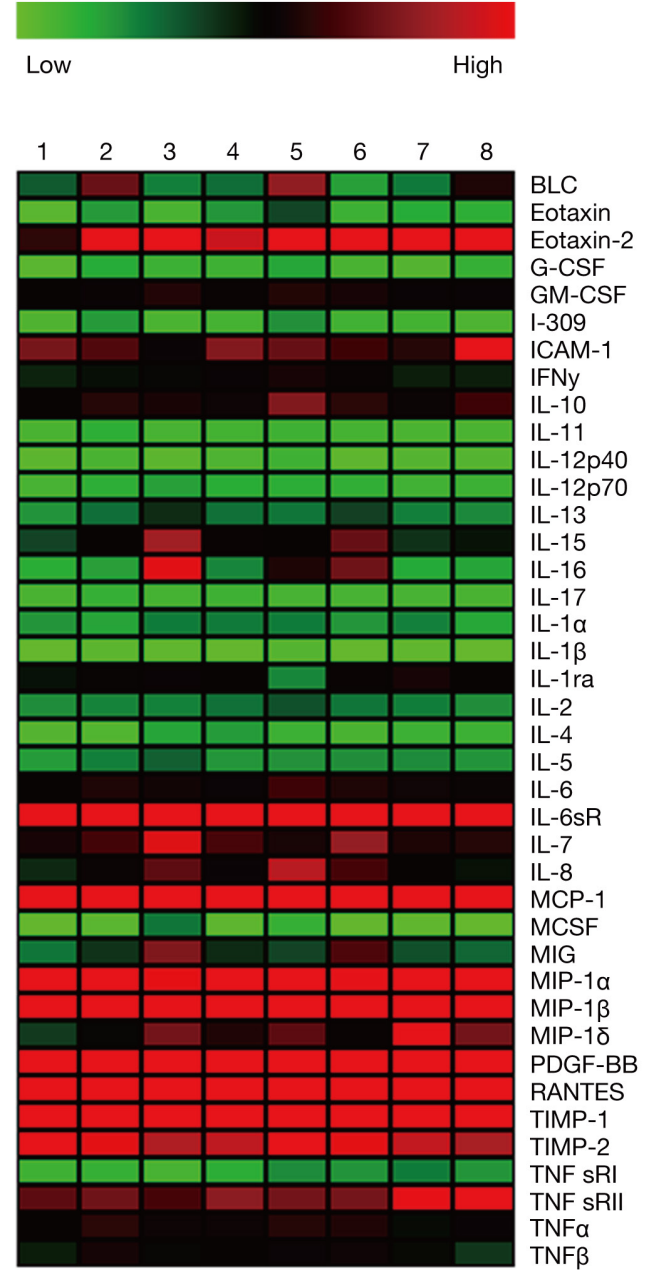

Fig. 1 Comparison of 40 inflammation-related cytokines between obese (Nos. 5-8) and lean (Nos. 1-4) children. Note: Color changes from green to red response the changes of cytokines levels from low to high in the samples.

\section{Validation of cytokines by ELISA}

The serum levels of sTNFR1 and sTNFR2 were further confirmed by ELISA for the respective differences found in the array analysis. The results reveal that obese children have significantly higher sTNFR1 levels than lean children ( $p=0.003$; Table 1; Fig. 2A). However, the level of sTNFR2 is not significantly changed between the two groups ( $p=0.069$; Table 1). Stratified analysis by gender shows that obese girls have higher sTNFR1 and sTNFR2 compared with lean girls ( $p=0.005, p=0.049$, respectively; Table 2, Fig. $2 \mathrm{~B}-2 \mathrm{C})$. However, there is no significant difference in serum levels of sTNFR1 and sTNFR2 between obese and lean boys.
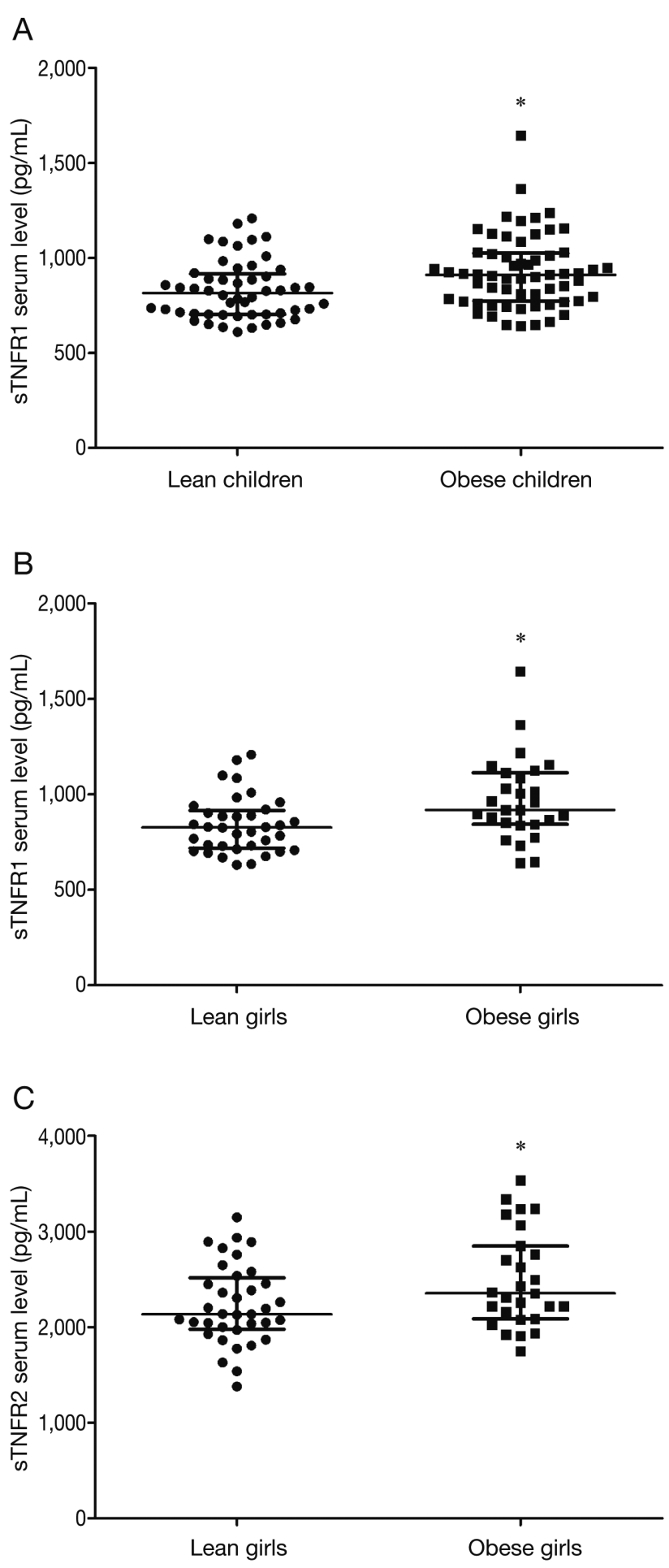

Fig. 2 Higher sTNFR1 (A) serum levels in children with obesity compared with controls. Girls with obesity presented higher sTNFR1 (B) and sTNFR2 (C) serum levels in comparison with lean girls using stratified analysis by gender. Note: The figure shows median and interquartile ranges. $* p<0.05$, Mann-Whitney $\mathrm{U}$ test. sTNFR, soluble tumor necrosis factor- $\alpha$ receptor. 
Table 2 Stratified analysis by gender

\begin{tabular}{|c|c|c|c|c|c|c|}
\hline & \multicolumn{3}{|c|}{ Girls $(N=63)$} & \multicolumn{3}{|c|}{ Boys $(\mathrm{N}=50)$} \\
\hline & Lean $(\mathrm{N}=36)$ & Obese $(\mathrm{N}=27)$ & $P$ & Lean $(\mathrm{N}=16)$ & Obese $(\mathrm{N}=34)$ & $P$ \\
\hline Age (month), n & $40.1 \pm 2.9$ & $39.8 \pm 2.9$ & $0.721^{\mathrm{a}}$ & $39.4 \pm 3.6$ & $39.9 \pm 3.1$ & $0.634^{\mathrm{a}}$ \\
\hline BMI $\left(\mathrm{kg} / \mathrm{m}^{2}\right)$, mean $\pm \mathrm{SD}$ & $14.1 \pm 0.5$ & $21.0 \pm 2.1$ & $<0.001^{\mathrm{a}}$ & $14.0 \pm 0.8$ & $21.3 \pm 2.2$ & $<0.001^{\mathrm{a}}$ \\
\hline sTNFR1, pg/mL $\left(\mathrm{P}_{25}-\mathrm{P}_{75}\right)$ & $827.6(718.0-916.3)$ & $918.7(842.8-1,113.7)$ & $0.005^{b}$ & $745.3(668.9-926.1)$ & 898.7 (753.7-975.3) & $0.082^{b}$ \\
\hline sTNFR2, pg/mL $\left(\mathrm{P}_{25}-\mathrm{P}_{75}\right)$ & $2,136.0(1,978.0-2,516.3)$ & $2,353.6(2,086.5-2,848.2)$ & $0.049^{b}$ & $2,285.4(1,820.6-2,545.2)$ & $2,212.7(2,081.7-2,639.6)$ & $0.603^{b}$ \\
\hline
\end{tabular}

$\mathrm{P}_{25}$, 25th percentile; $\mathrm{P}_{75}$, 75th percentile; $\mathrm{BMI}$, body mass index; sTNFR, soluble tumor necrosis factor - $\alpha$ receptor.

${ }^{\text {a }}$ Student $t$ test, ${ }^{\mathrm{b}}$ Mann-Whitney test

\section{Discussion}

TNF- $\alpha$ is the prototype of pro-inflammatory cytokine primarily produced by different cellular sources, including macrophages and lymphocytes. TNF- $\alpha$ exerts its effects through membrane-bound TNF receptors (TNFR) 1 and 2 [11]. TNFR1 and TNFR2 both contain four cysteine-rich repeats in their extracellular domains, forming elongated shapes that interact with the lateral grooves of the TNF- $\alpha$ trimer formed between two of its three protomers [12]. Soluble forms of the receptors (i.e., sTNFR1, sTNFR2) also exist in blood and can bind to TNF- $\alpha$ [13].

In the present study, we validated a multiplex cytokine assay for the detection of human inflammatory cytokines, and identified two novel cytokines (i.e., sTNFR1 and sTNFR2) in obese children aged 36-48 months. To the best of our knowledge, this is the first study to describe the association between sTNFRs and preschool childhood obesity. Some previous studies on the relationship between sTNFRs and human obesity have been performed, although their subjects are mostly adults, adolescents and older children. Some of these studies found that circulating sTNFR1 levels significantly increased in overweight/obese subjects, compared with their controls [14-18]. Meanwhile, other studies found significantly decreased circulating levels of sTNFR1 in obese subjects after performing weight loss intervention [19-21]. The abovementioned findings are in accordance with our findings, that is, obese children have a significant elevation in the serum levels of sTNFR1 compared with lean children. However, several other researchers [22-24] observed no difference of circulating sTNFR1 in the two groups (obese $v s$. lean). An increased level but no significant difference of serum sTNFR2 was observed in obese children compared with controls. The previous studies on the association between sTNFR2 and obesity also presented conflicting findings. Some studies reported that the levels of circulating sTNFR2 are significantly elevated in obese children, adolescents and adults $[15,17$, 18, 20-22], whereas others found inconsistent results, i.e., sTNFR2 is not related to obesity [19, 23-26]. The inconsistent clinical findings of sTNFRs may attributed to the obesity phenotype $[27,28]$, degree of obesity $[26,27]$, gender [7, 17, 29], age [7], genetic and environmental factors [28], etc. The present study focused on the subjects distributed at a subdivided age (36-48 months) to demonstrate a decrease in age- and environment-related interference and provide reliable results.

Moreover, the significant elevation of serum sTNFR1 levels was only observed in obese girls based on the stratified analysis by gender. Interestingly, a marginally significant difference of sTNFR2 appeared between obese girls and lean girls, although serum sTNFR2 was not significantly correlated with obesity in all of the children. This finding indicates that the circulating inflammation cytokine response exhibits sexual dimorphism in obese children. Some previous studies have explored the sexual differences of circulating sTNFRs with human obesity $[17,28,29]$. In addition, other inflammatory markers, such as IL-10, TNF- $\alpha$, IL-6, IL-8, and CRP, exhibit sexual dimorphism [3032]. The mechanisms underlying these sexual dimorphisms may be multifactorial, such as the release of different hormones. Sex hormones have important interactions with the immune system and modulate the inflammatory response [30]. Sex hormone levels are relatively lower in childhood compared with other stages. However, the estradiol level in girls is apparently higher than the testosterone level in boys among children aged 3-4 years [33]. Estrogens may exhibit diverse effects on inflammation and immune response [32]. The results of the present study suggest that obese girls may be more sensitive to obesityrelated inflammatory response than obese boys. Pamir et al. [34] demonstrated that TNFRs play a physiological role to limit body weight and adiposity by mod- 
estly increasing the metabolic rate and fatty acid oxidation. sTNFRs at low concentrations can stabilize TNF- $\alpha$ activity by gradually binding/releasing this cytokine. However, high amounts of these receptors antagonize the biological effects of TNF- $\alpha$. STNFR1 and sTNFR2 are released in response to changing levels of TNF- $\alpha$ [35]. In the present study, cytokine array analysis revealed no significant difference $(p=0.2)$ in serum TNF- $\alpha$ between both groups (obese vs. lean). In consideration that further analysis to validate the serum level of TNF- $\alpha$ by ELISA was not performed, the associations of TNF- $\alpha$ with obesity in children, as well as with the sTNFR1 and sTNFR2 levels, were not assessed in the present study.

Moreover, some other studies have investigated the associations between circulating sTNFRs and other diseases, such as insulin resistance $[17,24,36]$, metabolic syndrome [37] and type 2 diabetes [38], in patients with or without obesity. In the present study, preschool children aged 36-48 months were recruited to explore the association between serum inflammatory cytokines and obesity. The involvement of preschool children provides an excellent opportunity to study inflammatory changes during the early stages of obesity, without the confounding effects of lifestyle habits (e.g., smoking and co-existing inflammatory conditions). Furthermore, the interference factors, i.e., age and gender, are reduced by narrowing the age range and conducting stratified analyses, respectively.

However, several limitations of the present study should be considered. First, the sample size should be enlarged because of the marginal significance ( $p=$ 0.048 ) of sTNFR2 and the decreased power in the stratified analysis. Second, only the two cytokines (i.e., sTNFR1, sTNFR2) were validated in this study for $p<$ 0.05 . Those cytokines with larger $p$ values (e.g., $0.05<$ $p<0.1$ ) should be further validated using ELISA.

Altogether, the present results demonstrate that serum sTNFR1 is elevated in early childhood obesity. Moreover, serum sTNFR1 and sTNFR2 are associated with obesity in girls but not in boys, thereby suggesting that serum sTNFRs in early childhood obesity may be sex related.

\section{Acknowledgments}

This work was supported by the National Basic Research Program of China "973"[2013CB530605].

\section{Disclosure}

None of the authors have any potential conflicts of interest associated with this research.

\begin{tabular}{lcccc} 
Supplementary Table 1 & $\begin{array}{l}\text { The characteristics of participants and the results of inflammatory array including } 40 \\
\text { cytokines in the discovery set }\end{array}$ & & & \\
\hline & Lean $(\mathrm{N}=4)$ & Obese $(\mathrm{N}=4)$ & $P^{\text {a }}$ & Fold change $^{\text {b }}$ \\
\hline Age (month), mean \pm SD & $38.7 \pm 2.5$ & $39.3 \pm 2.7$ & - & - \\
Gender (male/female) & $2 / 2$ & $2 / 2$ & - & - \\
\hline BMI $\left(\mathrm{kg} / \mathrm{m}^{2}\right)$, mean \pm SD & $14.0 \pm 0.5$ & $23.2 \pm 1.5$ & - & 1.2 \\
BLC & $267.1 \pm 213.9$ & $332.3 \pm 280.0$ & 0.362 & 1.5 \\
Eotaxin & $70.7 \pm 44.3$ & $103.6 \pm 70.0$ & 0.229 & 1.6 \\
Eotaxin-2 & $1,253.0 \pm 730.5$ & $1,969.0 \pm 725.6$ & 0.107 & 1.1 \\
G-CSF & $53.6 \pm 23.7$ & $56.4 \pm 27.2$ & 0.440 & 1.1 \\
GM-CSF & $323.3 \pm 42.8$ & $341.9 \pm 38.6$ & 0.271 & 1.1 \\
I-309 & $55.8 \pm 33.3$ & $63.9 \pm 38.0$ & 0.379 & 1.2 \\
ICAM-1 & $532.2 \pm 156.7$ & $635.6 \pm 319.5$ & 0.291 & 1.1 \\
IFN $\gamma$ & $275.5 \pm 24.0$ & $291.1 \pm 48.4$ & 0.292 & 1.5 \\
IL-10 & $362.2 \pm 80.4$ & $538.9 \pm 286.0$ & 0.140 & 0.9 \\
IL-11 & $51.6 \pm 14.2$ & $44.2 \pm 7.3$ & 0.195 & 1.1 \\
IL-12p40 & $29.6 \pm 10.6$ & $32.2 \pm 15.6$ & 0.397 & 0.9 \\
IL-12p70 & $71.8 \pm 22.3$ & $61.8 \pm 9.1$ & 0.218 & 0.9 \\
IL-13 & $165.7 \pm 51.2$ & $157.2 \pm 38.6$ & 0.400 & 0.9 \\
IL-15 & $389.8 \pm 247$ & $340.5 \pm 163.2$ & 0.375 & 0.9 \\
IL-16 & $313.4 \pm 423.0$ & $288.7 \pm 249.4$ & 0.462 & 0.9 \\
IL-17 & $51.0 \pm 9.1$ & $43.5 \pm 1.5$ & 0.077 & 0.9
\end{tabular}


Supplementary Table 1 Cont.

\begin{tabular}{lcccc}
\hline & Lean $(\mathrm{N}=4)$ & Obese $(\mathrm{N}=4)$ & $P^{\mathrm{a}}$ & Fold change $^{\mathrm{b}}$ \\
\hline IL-1 $\alpha$ & $122.4 \pm 24.8$ & $119.2 \pm 24.5$ & 0.429 & 1.0 \\
IL-1 $\beta$ & $13.8 \pm 5.3$ & $14.4 \pm 9.9$ & 0.456 & 1.0 \\
IL-1ra & $287.4 \pm 18.2$ & $268.0 \pm 97.0$ & 0.354 & 0.9 \\
IL-2 & $137.1 \pm 13.9$ & $151.4 \pm 31.2$ & 0.217 & 1.1 \\
IL-4 & $63.7 \pm 39.8$ & $53.3 \pm 7.9$ & 0.313 & 0.8 \\
IL-5 & $132.4 \pm 32.9$ & $119.1 \pm 4.6$ & 0.228 & 0.9 \\
IL-6 & $331 \pm 39.5$ & $376.4 \pm 62.0$ & 0.131 & 1.1 \\
IL-6sR & $7,971.7 \pm 225.5$ & $8,332.1 \pm 327.5$ & 0.060 & 1.0 \\
IL-7 & $565.7 \pm 252.6$ & $461.6 \pm 172.5$ & 0.261 & 0.8 \\
IL-8 & $357.9 \pm 135.3$ & $468.1 \pm 258.4$ & 0.239 & 1.3 \\
MCP-1 & $1,391.0 \pm 373.5$ & $1,389.3 \pm 252.5$ & 0.497 & 1.0 \\
MCSF & $49.3 \pm 65.6$ & $23.9 \pm 25.4$ & 0.249 & 0.5 \\
MIG & $317.7 \pm 227.2$ & $270.1 \pm 159.2$ & 0.372 & 0.9 \\
MIP-1 $\alpha$ & $1,514.0 \pm 621.0$ & $1,668.9 \pm 602.6$ & 0.366 & 1.1 \\
MIP-1 $\beta$ & $1,643.3 \pm 640.7$ & $1,824.1 \pm 1,115.5$ & 0.394 & 1.1 \\
MIP-1 $\delta$ & $374.8 \pm 174.5$ & $611.5 \pm 277.2$ & 0.099 & 1.6 \\
PDGF-BB & $14,122.4 \pm 1,229.3$ & $11,999.6 \pm 3,179.9$ & 0.130 & 0.8 \\
RANTES & $11,314.9 \pm 782.1$ & $9,537.2 \pm 2,685.2$ & 0.125 & 0.8 \\
TIMP-1 & $3,853.9 \pm 917.3$ & $2,979.2 \pm 702.0$ & 0.090 & 0.8 \\
TIMP-2 & $919.7 \pm 128.6$ & $953.9 \pm 194.7$ & 0.390 & 1.0 \\
TNF sRI & $58.2 \pm 12.6$ & $123.0 \pm 14.0$ & 0.000 & 2.1 \\
TNF sRII & $582.9 \pm 86.0$ & $807.0 \pm 209.9$ & 0.048 & 1.4 \\
TNF $\alpha$ & $338.1 \pm 50.8$ & $340.8 \pm 57.0$ & 0.473 & 1.0 \\
\hline TNF $\beta$ & $294.0 \pm 42.0$ & $288.5 \pm 48.8$ & 0.434 & 1.0 \\
\hline BMI $b 0 d y ~$ & & & \\
\hline
\end{tabular}

BMI, body mass index; 40 cytokines, refer to Quantibody® Human Inflammation Array-3 (RayBiotech, Inc., USA). ${ }^{\mathrm{a}} p$ value for student' $t$ test between two groups (obese $v s$. lean), ${ }^{\mathrm{b}}$ The ratio of average level of cytokines between two groups (obese $v s$. lean)

\section{References}

1. Shoelson SE, Lee J, Goldfine AB (2006) Inflammation and insulin resistance. $J$ Clin Invest 116: 1793-1801.

2. Hotamisligil GS (2006) Inflammation and metabolic disorders. Nature 444: 860-867.

3. Wellen KE, Hotamisligil GS (2005) Inflammation, stress, and diabetes. $J$ Clin Invest 115: 1111-1119.

4. Frohlich M, Imhof A, Berg G, Hutchinson WL, Pepys $\mathrm{MB}$, et al. (2000) Association between C-reactive protein and features of the metabolic syndrome: a population-based study. Diabetes Care 23: 1835-1839.

5. Ouchi N, Parker JL, Lugus JJ, Walsh K (2011) Adipokines in inflammation and metabolic disease. Nat Rev Immunol 11: 85-97.

6. Skinner AC, Steiner MJ, Henderson FW, Perrin EM (2010) Multiple markers of inflammation and weight status: cross-sectional analyses throughout childhood. Pediatrics 125: e801-809.

7. Tam CS, Clement K, Baur LA, Tordjman J (2010) Obesity and low-grade inflammation: a paediatric perspective. Obes Rev 11: 118-126.

8. Utsal L, Tillmann V, Zilmer M, Maestu J, Purge P, et al. (2012) Elevated serum IL-6, IL-8, MCP-1, CRP, and IFN-gamma levels in 10- to 11-year-old boys with increased BMI. Horm Res Paediatr 78: 31-39.

9. Bocca G, Corpeleijn E, Stolk RP, Wolffenbuttel BH, Sauer PJ (2014) Effect of obesity intervention programs on adipokines, insulin resistance, lipid profile, and lowgrade inflammation in 3- to 5-y-old children. Pediatr Res 75: 352-357.

10. Li H, Zong XN, Ji CY, Mi J (2010) [Body mass index cut-offs for overweight and obesity in Chinese children and adolescents aged 2 - 18 years]. Zhonghua Liu Xing Bing Xue Za Zhi 31: 616-620 (In Chinese).

11. Tartaglia LA, Goeddel DV (1992) Two TNF receptors. Immunol Today 13: 151-153.

12. Banner DW, D'arcy A, Janes W, Gentz R, Schoenfeld HJ, et al. (1993) Crystal structure of the soluble human 55 kd TNF receptor-human TNF beta complex: implications for TNF receptor activation. Cell 73: 431-445.

13. Tracey KJ, Cerami A (1994) Tumor necrosis factor: a pleiotropic cytokine and therapeutic target. Annu Rev Med 45: 491-503.

14. Tsaoussoglou M, Bixler EO, Calhoun S, Chrousos GP, Sauder K, et al. (2010) Sleep-disordered breathing in 
obese children is associated with prevalent excessive daytime sleepiness, inflammation, and metabolic abnormalities. J Clin Endocrinol Metab 95: 143-150.

15. Jermendy A, Korner A, Kovacs M, Kaszas E, Balazsovics J, et al. (2010) Association between tolllike receptor polymorphisms and serum levels of tumor necrosis factor-alpha and its soluble receptors in obese children. Med Sci Monit 16: CR180-185.

16. Malavazos AE, Corsi MM, Ermetici F, Coman C, Sardanelli F, et al. (2007) Proinflammatory cytokines and cardiac abnormalities in uncomplicated obesity: relationship with abdominal fat deposition. Nutr Metab Cardiovasc Dis 17: 294-302.

17. Dzienis-Straczkowska S, Straczkowski M, Szelachowska M, Stepien A, Kowalska I, et al. (2003) Soluble tumor necrosis factor-alpha receptors in young obese subjects with normal and impaired glucose tolerance. Diabetes Care 26: 875-880.

18. Tanaka S, Isoda F, Ishihara Y, Kimura M, Yamakawa T (2001) T lymphopaenia in relation to body mass index and TNF-alpha in human obesity: adequate weight reduction can be corrective. Clin Endocrinol (Oxf) 54: 347-354.

19. Ryan AS, Nicklas BJ (2004) Reductions in plasma cytokine levels with weight loss improve insulin sensitivity in overweight and obese postmenopausal women. Diabetes Care 27: 1699-1705.

20. Fisher G, Hyatt TC, Hunter GR, Oster RA, Desmond RA, et al. (2011) Effect of diet with and without exercise training on markers of inflammation and fat distribution in overweight women. Obesity (Silver Spring) 19: 1131-1136.

21. Van Meijl LE, Mensink RP (2010) Effects of low-fat dairy consumption on markers of low-grade systemic inflammation and endothelial function in overweight and obese subjects: an intervention study. $\mathrm{Br} J \mathrm{Nutr}$ 104: 1523-1527.

22. Schipper HS, Nuboer R, Prop S, Van Den Ham HJ, De Boer FK, et al. (2012) Systemic inflammation in childhood obesity: circulating inflammatory mediators and activated CD14++ monocytes. Diabetologia 55: 2800-2810.

23. Huang F, Del-Rio-Navarro BE, Perez-Ontiveros JA, Ruiz-Bedolla E, Saucedo-Ramirez OJ, et al. (2014) Effect of six-month lifestyle intervention on adiponectin, resistin and soluble tumor necrosis factor-alpha receptors in obese adolescents. Endocr J 61: 921-931.

24. Hauner H, Bender M, Haastert B, Hube F (1998) Plasma concentrations of soluble TNF-alpha receptors in obese subjects. Int J Obes Relat Metab Disord 22: 1239-1243.

25. Fischer CP, Berntsen A, Perstrup LB, Eskildsen P, Pedersen BK (2007) Plasma levels of interleukin-6 and C-reactive protein are associated with physical inactivity independent of obesity. Scand J Med Sci Sports 17: 580-587.
26. Olszanecka-Glinianowicz M, Zahorska-Markiewicz B, Janowska J, Zurakowski A (2004) Serum concentrations of nitric oxide, tumor necrosis factor (TNF)-alpha and TNF soluble receptors in women with overweight and obesity. Metabolism 53: 1268-1273.

27. Cartier A, Cote M, Bergeron J, Almeras N, Tremblay A, et al. (2010) Plasma soluble tumour necrosis factoralpha receptor 2 is elevated in obesity: specific contribution of visceral adiposity. Clin Endocrinol (Oxf) 72: 349-357.

28. Ronnemaa T, Pulkki K, Kaprio J (2000) Serum soluble tumor necrosis factor-alpha receptor 2 is elevated in obesity but is not related to insulin sensitivity: a study in identical twins discordant for obesity. J Clin Endocrinol Metab 85: 2728-2732.

29. Corica F, Allegra A, Corsonello A, Buemi M, Calapai G, et al. (1999) Relationship between plasma leptin levels and the tumor necrosis factor-alpha system in obese subjects. Int J Obes Relat Metab Disord 23: 355-360.

30. Lefevre N, Corazza F, Duchateau J, Desir J, Casimir G (2012) Sex differences in inflammatory cytokines and CD99 expression following in vitro lipopolysaccharide stimulation. Shock 38: 37-42.

31. Trotter A, Muck K, Grill HJ, Schirmer U, Hannekum A, et al. (2001) Gender-related plasma levels of progesterone, interleukin- 8 and interleukin-10 during and after cardiopulmonary bypass in infants and children. Crit Care 5: 343-348.

32. Casimir GJ, Lefevre N, Corazza F, Duchateau J (2013) Sex and inflammation in respiratory diseases: a clinical viewpoint. Biol Sex Differ 4: 16.

33. Ober C, Loisel DA, Gilad Y (2008) Sex-specific genetic architecture of human disease. Nat Rev Genet 9: 911-922.

34. Pamir N, Mcmillen TS, Kaiyala KJ, Schwartz MW, Leboeuf RC (2009) Receptors for tumor necrosis factor-alpha play a protective role against obesity and alter adipose tissue macrophage status. Endocrinology 150: 4124-4134.

35. Aderka D (1996) The potential biological and clinical significance of the soluble tumor necrosis factor receptors. Cytokine Growth Factor Rev 7: 231-240.

36. Fernandez-Real JM, Broch M, Ricart W, Casamitjana R, Gutierrez C, et al. (1998) Plasma levels of the soluble fraction of tumor necrosis factor receptor 2 and insulin resistance. Diabetes 47: 1757-1762.

37. You T, Ryan AS, Nicklas BJ (2004) The metabolic syndrome in obese postmenopausal women: relationship to body composition, visceral fat, and inflammation. $J$ Clin Endocrinol Metab 89: 5517-5522.

38. Plomgaard P, Nielsen AR, Fischer CP, Mortensen OH, Broholm C, et al. (2007) Associations between insulin resistance and TNF-alpha in plasma, skeletal muscle and adipose tissue in humans with and without type 2 diabetes. Diabetologia 50: 2562-2571. 